\title{
Integrative and interruptive mechanisms in peripheral and hemispheric masking
}

\author{
JEFFREY S. KLINE \\ University of California, San Francisco, California \\ and \\ DENNIS P. SACCUZZO \\ San Diego State University, San Diego, California
}

\begin{abstract}
Integrative and interruptive mechanisms in color masking were examined in peripheral and hemispheric locations in the visual system. Fifteen female college students participated in two experiments. Both experiments entailed tachistoscopic presentations of color stimuli over increasing stimulus onset asynchronies (SOAs). Experiment 1 involved binocular presentations of red and green stimuli of equal size and energy. The shortest SOA revealed integration of the stimuli which rendered the colors indistinguishable. Moderate SOAs resulted in a backward-mask suppression of the initial color stimuli, indicative of interruptive mechanisms. So that we could investigate contralateral masking, Experiment 2 involved presentations of color stimuli followed by either a black mask presented in the opposite visual field or a homogeneous light-mask control. No masking trends were found. However, a significant visual field $\times$ mask type interaction suggested differential masking processes between hemispheres that can be explained by their unique manners of processing and by integration and interruption theories.
\end{abstract}

Since a sensory memory store was discovered through the use of partial report procedures (Sperling, 1960), there have been a variety of techniques developed to investigate the mechanisms of a short-term sensory store (Coltheart, 1980; Long, 1980) and information transfer through the use of techniques such as visual backward masking (Felsten \& Wasserman, 1980). One largely unexplored procedure in this regard involves the use of color. Although color information has routinely been utilized as a selection criterion in studies using partial report (Banks \& Barber, 1977; Clark, 1969; Coltheart, Lea, \& Thompson, 1974; Von Wright, 1968), it has been employed far less often with masking procedures (Bevan, Janides, \& Collyer, 1970; Teft, 1969). Furthermore, color masking has not been examined in alternate cerebral hemispheres, even though there is some evidence that masking can occur using target letters and pattern masks when they are presented simultaneously in contralateral visual fields (Saccuzzo, Michael, \& Rowe, 1982).

Integration and interruption theories (Eriksen \& Schultz, 1978; Kahneman, 1968) have dominated the explanations of visual masking. Some investigators do not consider these two theories to be mutally exclusive but believe they are compatible in describing where, when, and how masking operates (Liss, 1968; Scheerer, 1973; Spencer \& Shuntich, 1970; Turvey, 1973). The current study examined the possibility of integrative and interruptive

This research was based on a master's thesis conducted by the first author at San Diego State University. Address correspondence to Dennis P. Saccuzzo, Department of Psychology, San Diego State University, San Diego, CA 92182. mechanisms working contiguously both in the peripheral visual system and in alternate brain hemispheres.

Experiment 1 was designed to investigate peripheral mechanisms in binocular masking where red and green stimuli of equal size and energy were presented over increasing stimulus onset asynchronies (SOAs) to the center of the subject's visual field. We predicted that when SOAs were short, the stimuli would integrate. However, as the SOA increased and the information traveled to deeper levels of the visual system, we predicted that there would be a backward, rather than a forward, mask suppression of the initial color stimuli, implicating the operation of interruptive mechanisms (Felsten \& Wasserman, 1980; Schiller \& Smith, 1965; Sharf \& Lefton, 1970; Spencer \& Shuntich, 1970; Teft, 1969). The longer SOAs were expected to reveal the approximate speed at which the first stimulus was able to be completely processed and the color disinctly recognized.

\section{EXPERIMENT 1}

\footnotetext{
Method

Subjects. Seven females who were enrolled in introductory psychology classes at San Diego State University acted as subjects for this experiment. They were between the ages of 17 and 25 .

Screening measures. The subjects for both experiments were tested on the Snellen eye chart for visual acuity. None failed more than two items on the 20/30 row when standing at a distance of $20 \mathrm{ft}$ from the chart. They were also screened with the Ishihari color-blindness test as adapted by Coon (1980) and were found to have normal color discrimination abilities.

Apparatus and materials. A Gerbrands (Model T-3B-1) three-field tachistoscope was employed for stimulus presentations. The fixation and
} 
stimulus fields had equal luminances of $51.37 \mathrm{~cd} / \mathrm{m}^{2}$. The fixation point was centered on the preexposure field and consisted of a minute, finely penciled cross. Viewing distance was $89 \mathrm{~cm}$. Color disk stimuli consisted of circular patches of Colormatch paper mounted on $5 \times 7$ in. white index cards. The red and green colors were chosen in the following manner. First, various colors were selected based on Munsell (1965) notations, which came as close as possible to the red and green that Banks and Barber (1977) utilized. A check for color equivalence was carried out based on Bevan et al.'s (1970) findings that various hues, even though matched on the Munsell values, differed in detectability. Scotopic similarity of the colors was determined by examining them under light conditions in which there was a loss of foveal vision. Three pilot subjects reported subjective equivalence as viewed at scotopic luminance levels through the tachistoscope. The colors matched Munsell notations of 5R 5/12 (red) and 5G 5/8 (green).

Procedure. The mask and target stimuli subtended equal visual angles of approximately $2^{\circ}$, and each was exposed for $30 \mathrm{msec}$. The red and green stimuli were presented at the same spatial region so that their boundaries coincided. Tachistoscopic superimposition of the stimuli resulted in a single dark gray disk devoid of color, consistent with what would be expected from subtractive color mixture. The stimuli were successively presented in the center of the visual field with SOA intervals of 30, 50, 70, 110, 190, and $230 \mathrm{msec}$. Each trial consisted of the following stimulus presentation sequence: fixation, target (red or green), fixation (SOA), stimulus (opposite color), fixation. After the screening procedures and during a 10-min dim-adaptation period, the subjects were instructed to report after each trial a number from 1 to 5 , for example, " 1,5 " or " 5,1 ." The number 1 was designated as green, 2 was grayish green, 3 was gray, 4 was grayish red, and 5 was red. The answer " 1 , 5 " meant that the subject saw green first and then red, whereas the answer " 5,1 " meant the opposite. Six blocks (one for each SOA) of 10 trials each were presented for practice and were counterbalanced across subjects. In each block of 10 trials, stimulus presentations were randomized so that 5 trials were in the order green-red and 5 in the order red-green. Formal testing was similar to the practice period, except that each of the six blocks that corresponded to the SOA levels contained 20 trials instead of 10 . The blocks were presented in a different sequence from that of the practice trials and again were counterbalanced across subjects. Within each block of 20 trials, 10 stimulus presentations were in the order green-red and 10 were in the order red-green in a randomized sequence.

\section{Results}

Inspection of the data before analysis revealed that the subjects overwhelmingly responded with a single answer choice 1 to 5 at SOA levels of 30,50 , and $70 \mathrm{msec}$, indicating that the subjects saw a single percept. However, at 110,190 , and $230 \mathrm{msec}$, the subjects predominantly responded with the " 1,5 " or " 5,1 "' answer choices, indicating that they saw two color percepts at these intervals. Consequently, two separate analyses were conducted. First, the single-percept data was analyzed in a $3(\mathrm{SOA}) \times 2$ (red-green vs. green-red order of color presentation) repeated measures analysis of variance. A response on the scale of 1 to 5 served as the dependent measure. A significant difference was found due to the main effect of order of color presentation $[F(1,6)=16.44$, $p<.0067]$. The mean responses when red followed green and when green followed red were $3.72(S D=.55)$ and $2.69(S D=.79)$, respectively. The interaction of SOA $\times$ order of color presentation was also significant $[F(2,12)=9.59, p<.0032]$ (see Figure 1). A NewmanKeuls analysis of this interaction indicated that the differences in color ratings between the red-green and greenred color-order presentations showed up at SOA values

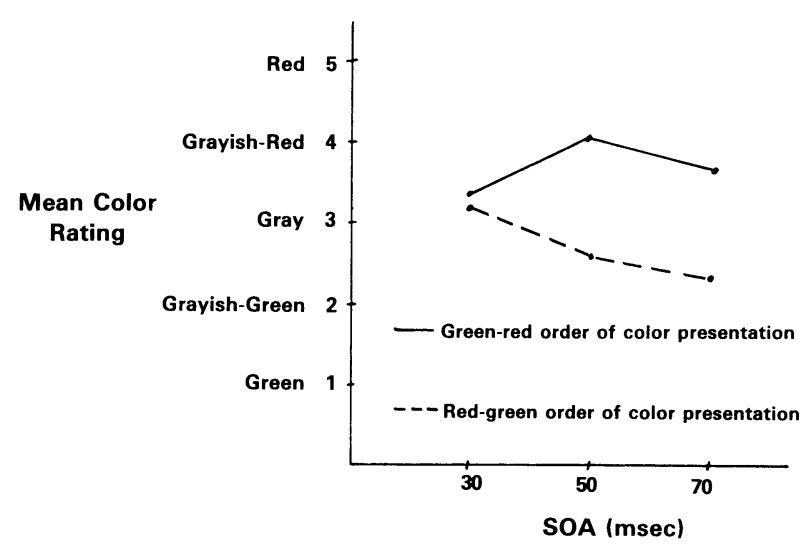

Figure 1. Mean color ratings as a function of stimulus onset asynchrony (SOA) for green-red and red-green color presentation order for Experiment 1.

of 50 (red-green $M=2.53$, green-red $M=4.06$; $p<.05$ ) and $70 \mathrm{msec}$ (red-green $M=2.36$, green-red $M=3.66, p<.05)$. At these values the observers' perceptions leaned toward the color presented second, whereas at an SOA value of $30 \mathrm{msec}$ there was no significant difference in color ratings for red-green versus green-red order of color presentation. The NewmanKeuls analysis also indicated that the mean color ratings for the red-green and green-red order of color presentations at an SOA value of $30 \mathrm{msec}$ (red-green $M=3.20$, green-red $M=3.44$ ) were significantly different from the mean color ratings of the red-green and green-red orders of color presentations at an SOA value of $50 \mathrm{msec}$, and significantly different from the mean color rating of the red-green order of color presentation at a 70-msec SOA $(p<.05)$. The mean color rating of the red-green order of color presentation at an SOA of $50 \mathrm{msec}$ was significantly different from the mean color rating for the green-red order at an SOA of $70 \mathrm{msec}(p<.05)$. Finally, the mean color rating for the green-red order at $50 \mathrm{msec}$ was significantly different from the mean color rating of the red-green order at an SOA of $70 \mathrm{msec}$ $(p<.05)$.

A second analysis was conducted to quantify whether the subjects perceived a single percept or two percepts across the six SOAs. Data transformations from the original " 1,5 " or " 5,1 " dependent variable responses were needed to test the hypothesis of no change in the percentage of favorable replies (in this case, two percepts) over the SOAs. For each cell $(n=10)$ the proportion of responses indicating the perception of two images was calculated. These data were then transformed based on the median of the proportions. The proportions above and below the median were supplanted by ones and zeros, respectively. Next, based on the obvious heteroscedasticity of the final data distribution, a Cochran's $Q$ analysis would have been appropriate. However, Winer (1971) indicated that treating the data as if it were normally distributed and computing an $F$ statistic would yield proba- 
bility statements relatively close to those obtained by use of a $Q$ statistic. For this reason the data were subjected to a $6(\mathrm{SOA}) \times 2$ (order of color presentation) repeated measures analysis of variance. A significant main effect was found due to SOA $[F(5,30)=74.44, p<.000]$. A Newman-Keuls analysis of the main effect for SOA level clearly indicated that a single percept was experienced at SOAs of 30, 50, and $70 \mathrm{msec}$ and that two percepts were seen at the longer SOA levels of 110,190 , and $230 \mathrm{msec}$. The transformed data values for SOAs of 30,50 , and $70 \mathrm{msec}$ were not significantly different from each other but were found to be significantly different from the data values for SOAs of 110,190 , and $230 \mathrm{msec}(p<.05)$. The data values for SOAs of 110,190 , and $230 \mathrm{msec}$ were also not significantly different from each other. Figure 2 illustrates the main effect due to SOA.

\section{Discussion}

The hypotheses for Experiment 1 were upheld. At an SOA level of $30 \mathrm{msec}$, the subjects' stimulus perceptions were neither clearly red nor clearly green. The information at this more peripheral level of the visual system integrated almost completely, thereby rendering the colors indistinguishable. The responses of the visual system to the color stimuli overlapped in time, summed as if they were presented simultaneously, and fused into a unified whole (Eriksen \& Schultz, 1978). A single stimulus was perceived for SOA values of 50 and 70 msec, but the subjects' color experience shifted according to a backward-masking rule. At these intervals interruptive mechanisms at higher levels of the visual system were dominant, thus effectively erasing the color of the initial stimulus. This explanation is based on past research, which indicates that backward masking occurs through the interruption of sensory signals at more central locations of information processing (Felsten \& Wasserman, 1980; Schiller \& Smith, 1965; Sharf \& Lefton, 1970; Spencer \& Shuntich, 1970 ), and on evidence that color masking is more effective with central than with peripheral mediation (Teft, 1969). It is important to remember that since the stimuli were of equal size and energy, forward masking rather than backward masking could have logically occurred. For color stimuli in this experiment, backward masking was more powerful. An SOA of $110 \mathrm{msec}$ demarcated the point at which the subjects' perceptual experience made a qualitative shift to the recognition of two distinct color images. Somewhere between the SOAs of 70 and $110 \mathrm{msec}$, the two stimuli split apart and were processed as discrete units, which resulted in the experience of both colors disjoined and in sequence. Recognition of the first stimulus at SOAs of $110 \mathrm{msec}$ and longer was because the visual system had sufficient time to transfer color informa-

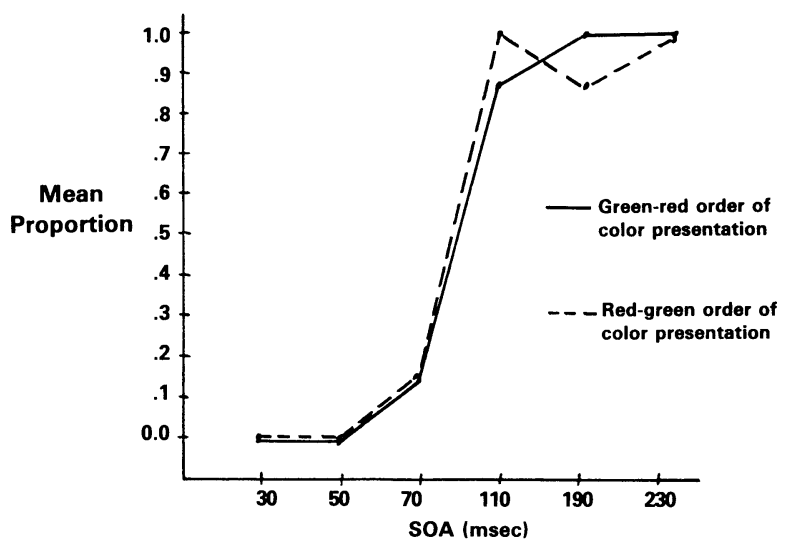

Figure 2. Mean proportion of responses indicating the recognition of two color percepts as a function of stimulus onset asynchrony (SOA) for green-red and red-green color presentation order for Experiment 1. tion into durable storage and to permit the subjects to read out this information and report the color of their percept (Coltheart, 1980). The approximate speed of full processing of the first color stimulus was $110 \mathrm{msec}$. In summary, this experiment revealed both integrative and interruptive mechanisms at work in peripheral-level color masking and offered a crude measure of cognitive speed.

Experiment 2 addressed the question of whether integrative and interruptive mechanisms could explain color masking in the right versus left cerebral hemisphere. The experiment was similar to other masking studies that varied the location of the stimulus presentations in the visual fields (Lefton, 1972; McFadden \& Gummerman, 1973; Polich, 1978; Proudfoot, 1982; Saccuzzo et al., 1982; Ward \& Ross, 1977), and it is a partial replication of the work by Saccuzzo et al. that examined masking in higher cortical regions. It is believed that presentations to opposite visual fields result in contralateral stimulus projections beyond Area 17 in the visual cortex (McFadden \& Gummerman, 1973; Saccuzzo et al., 1982). In addition to using color stimuli, this experiment included a homogeneous light-mask control to rule out light masking as an alternative explanation for the findings of Saccuzzo et al. A backward-masking function was expected for opposite visual field stimulus presentations using the black mask. A masking trend was not expected under the conditions of a homogeneous light mask that was flashed after a color was presented to either the right or left visual field. This experiment left open the possibility of differential masking processes between hemispheres.

\section{EXPERIMENT 2}

\section{Method}

Subjects. A new group of 8 females from ages 17 to 25 who were enrolled in introductory psychology classes at San Diego State University acted as subjects for this experiment. All subjects were right-handed and were screened in the same manner as were the subjects in Experiment 1.

Apparatus and materials. The same apparatus was used as in Experiment 1 . The black disk mask for Experiment 2 consisted of a solid circular disk cut from Colormatch paper matched to the Munsell notation $\mathrm{N} 2 / 0$. It was mounted on a $5 \times 7$ in white index card. The same color stimuli were used as in Experiment 1. The homogeneous light mask for Experiment 2 consisted of a blank white field equivalent in luminance to the fixation and stimulus fields. The black mask and the colored target stimuli subtended visual angles of $4^{\circ}$ and $2^{\circ}$, respectively. The target stimulus exposure duration was set at $5 \mathrm{msec}$ and the mask duration was modulated at $100 \mathrm{msec}$.

Procedure. The procedure for this experiment was similar to that used by Saccuzzo et al. (1982). The mask and target were presented to opposite visual fields $2^{\circ}$ to the right and left of the central fixation point. Each trial consisted of the following backward-masking stimulus sequence: fixation, target (red or green), fixation (SOA), mask (black disk or homogeneous light flash), fixation. After the screening procedures and during the dim-adaptation period, the subjects were instructed that a red or green circular stimulus would be flashed briefly to one side of a central point. They were told that on some trials a large black circular stimulus would be flashed on the opposite side and on some trials it would not. The subjects were informed that upon hearing a verbal "ready" signal, they were to fixate on the central cross. The importance of fixation was emphasized throughout testing. The trial commenced, and the subjects' task was to respond immediately by stating "red" or "green," according to the color they perceived. Twenty practice trials were then administered. Presentations of the homogeneous light mask and the black circular mask each followed the color stimulus for 10 of the trials. Five red stimulus presentations occurred with the black mask and five occurred with the homogeneous light mask. The same was true for green. Finally, the target stimulus was presented 10 times to the right and 10 times to the left visual field. Red was presented 5 times to the right visual field and 5 times to the left field. The same was true for the green target stimulus. Color, visual field, and mask were presented in random orders. Formal testing was broken into eight blocks of 20 trials. The light mask and black mask were presented for four blocks apiece. Each set of four blocks corresponded to the following SOA values: $5,15,25$, and $45 \mathrm{msec}$. Within a 20 -trial 
block, red and green stimuli were presented for 10 trials each. Likewise, the stimuli were presented 10 times to the left visual field and 10 times to the right field, so that red was presented to the right visual field for 5 trials and to the left field for 5 trials. The same was true for green. Mask, color, and visual field were presented in random orders across subjects.

\section{Results}

The number of correct color choice (red or green) responses was the dependent measure for each subject at all levels of the three independent variables. The data were analyzed in a 4 (SOA) $\times 2$ (visual field) $\times 2$ (mask type) repeated measures analysis of variance. Significance was found only for the interaction of visual field $\times$ mask type $[F(1,7)=38.50, p<.0004]$. The Newman-Keuls analysis of this interaction indicated clearly that for rightvisual-field target-stimulus presentations, greater masking effects occurred when the homogeneous light mask was flashed than when the black mask was presented to the opposite visual field. Conversely, upon left-visual-field target-stimulus presentations, greater masking effects occurred when the black mask was presented to the opposite visual field than when the homogeneous light mask was flashed. The mean number of correct responses for the right-visual-field black-mask condition $(M=6.44)$ was significantly different from that of the right-visualfield homogeneous-light-mask condition $(M=5.69)$, and left visual field, black mask condition $(M=5.47)$ $(p<.05)$. The mean number of correct responses for the left-visual-field homogeneous-light-mask condition $(M=6.09)$ was significantly different from the leftvisual-field black-mask condition $(M=5.47)$ and the right-visual-field homogeneous-light-mask condition $(M=5.69)(p<.05)$.

\section{Discussion}

The hypotheses for Experiment 2 unexpectedly were not supported. Masking functions were not found for either the black- or the homogeneous-light-mask conditions, and there were no significant differences in overall performance between these two. The possibility still exists that contralateral masking beyond Area 17 in the visual cortex, as found by Saccuzzo et al. (1982), may have been caused by the homogeneous flash of light that appeared in both visual fields along with the pattern mask when it was presented to the opposite field. However, a provocative serendipitous result was the strongly significant finding that the light mask was stronger when the color stimulus was projected to the left hemisphere, whereas the black mask was more powerful in right-hemisphere processing of the color. Interestingly, this suggests laterally differentiated iconic processing due to the type of mask that can be explained by integration and interruption theories. Integrative mechanisms were posited to have operated in the left hemisphere. Light masking in this hemisphere resulting from luminance summation and contrast reduction (Kahneman, 1968) was stronger, even though previous studies have shown that random noise and pattern masking are more powerful than light masking in peripheral locations (Schiller \& Smith, 1965). Conversely, the right hemisphere responded in a manner that could have been predicted from interruption theory of masking. The light mask was not powerful enough to summate with and degrade the color stimulus. However, the black mask was of high enough energy to more effectively erase the color percept. The right hemisphere efficiently received the black mask information from the left hemisphere, which then swiftly interrupted the processing of the initial color stimulus. These findings also suggest that masking mechanisms operate according to the nature of how each hemisphere uniquely processes information. How integrative and interruptive mechanisms work in unison between peripheral and cortical visual channels in color masking has yet to be explored.

\section{REFERENCES}

BANKS, W., \& BARBER, G. (1977). Color information in iconic memory. Psychological Review, 84, 536-546.

Bevan, W., Janides, D., \& Collyer, S. (1970). Chromatic relationships in metacontrast suppression. Psychonomic Science, 19, 367-368.

CLARK, S. (1969). Retrieval of color information from preperceptual memory. Journal of Experimental Psychology, 82, 263-266.

Coltheart, M. (1989). Iconic memory and visible persistence. Perception \& Psychophysics, 27, 183-228.

Coltheart, M., Lea, C., \& Thompson, K. (1974). In defense of iconic memory. Quarterly Journal of Experimental Psychology, 26, 633-641.

Coon, D. (1980). Introduction to psychology: Exploration and application. New York: West.

ERIKSEN, C., \& Schultz, D. (1978). Temporal factors in visual information processing: A tutorial review. In J. Requin (Ed.), Attention and performance VII. Hillsdale, $\mathrm{NJ}$ : Erlbaum.

Felsten, G., \& Wasserman, G. (1980). Visual masking: Mechanisms and theories. Psychological Bulletin, 88, 329-353.

KAHNEMAN, D. (1968). Methods, finding, and theory of studies of visual masking. Psychological Bulletin, 70, 404-425.

Lefton, L. (1972). Metacontrast: A review. Psychonomic Monograph Supplements, 14, (14, Whole No. 62).

Liss, P. (1968). Does backward masking by visual noise stop stimulus processing? Perception \& Psychophysics, 4, 328-330.

LONG, G. (1980). Iconic memory: A review and critique of the study of short-term visual storage. Psychological Bulletin, 88, 785-820.

McFadden, D., \& Gummerman, K. (1973). Monoptic and dichoptic metacontrast across the vertical meridian. Vision Research, 13, 185-196.

Munsell, A. (1965). A color notation: An illustrated system defining all colors and their relations by measurement scales of hue, value, and chroma. Munsell book of color. Baltimore: Munsell Color Co.

Polich, J. (1978). Hemispheric differences in stimulus identification. Perception \& Psychophysics, 24, 49-57.

ProudFoot, R. (1982). Hemispheric asymmetry for face recognition: Some effects of visual masking, hemiretinal stimulation, and learning task. Neuropsychologia, 20, 129-144.

Saccuzzo, D. P., Michael, B., \& Rowe, R. (1982). Visual masking with presentations in same and opposite visual fields: Evidence for contralateral masking. Perceptual \& Motor Skills, 55, 131-140.

SCHEERER, E. (1973). Integration, interruption and processing rate in visual backward masking. Psychologische Forschung, 36, 71-93.

SChiller, P. H., \& SMith, M. C. (1965). A comparison of forward and backward masking. Psychonomic Science, 3, 77-78.

ShaRF, B., \& LeFTON, L. (1970). Backward and forward masking as a function of stimulus and task parameters. Journal of Experimental Psychology, 84, 331-338.

SPENCER, T., \& SHUNTICH, R. (1970). Evidence for an interruption theory of backward masking. Journal of Experimental Psychology, 85, 198-203.

SPERLING, G. (1960). The information available in brief visual presentations. Psychological Monographs, 74, 1-29.

TEFT, L. (1969). The effects of stimulus hue on backward masking under conditions of monoptic and dichoptic stimulus presentations. Psychonomic Science, 16, 287-288.

Turvey, M. (1973). On peripheral and central processes in vision. Psychological Review, 80, 1-52.

VON WRIGHT, J. (1968). Selection in visual immediate memory. Quarterly Journal of Experimental Psychology, 20, 62-68.

WARD, T., \& Ross, L. (1977). Laterality differences and practice effects under central backward masking conditions. Memory \& Cognition, 5, 221-226.

WINER, B. (1971). Statistical principles of experimental design. New York: McGraw-Hill.

(Manuscript received for publication May 30, 1987.) 